\title{
Sustained attention: Stimulus control determined by schedule of cue production interacting with cue duration
}

\author{
WILLIAM S. MAKI, JR. \\ North Dakota State University, Fargo, North Dakota 58102
}

\begin{abstract}
In a study of sustained attention ("vigilance"), pigeons performed a conditional discrimination in a 3-key operant chamber. Pecking a white center key initiated a $0.2-$ or 2.0 -sec cue (a red or green disk). The side keys then displayed white disks, and a peck on the right or left key was reinforced depending on whether the preceding cue was red or green. Pecks on the white center key initiated the cue according to one of two schedules of cue production (FR 1 or VI $7.5 \mathrm{sec}$ ). Control of side key choices by 0.2 -sec cues was disturbed by transition from FR 1 to VI 7.5, and recovered after the schedule of cue production changed from VI 7.5 back to FR 1 . Control of choices by 2.0 -sec cues was not affected by changing schedules of cue production. Rates of pecking the cue were higher than rates of cue-producing responses.
\end{abstract}

Posner and Boies (1971) recently pointed to three ways in which the term attention has been used in experimental psychology. First, "selective attention" is invoked to account for instances in which an organism's behavior is controlled by some stimuli but not by others. Second, an organism may be regarded as analogous to an information-processing channel of limited capacity, meaning that organisms have difficulty attending to more than one thing at a time. A third use of "attention" refers to processes underlying protracted performances during which organisms must observe a stimulus source, i.e., remain "vigilant." All of these are well researched areas of human experimental psychology (for reviews see Lindsay, 1970, and Swets \& Kristofferson, 1970).

It appears that most previous work with animals has been concerned with the selective attention meaning (Sutherland \& Mackintosh, 1971). However, some work with animals has been done in the context of the second meaning and has viewed nonhumans as limited capacity information processing channels (Maki \& Leuin, 1972). This work has been described as involving "shared attention" (Maki \& Leith, 1973). The third meaning of attention, "sustained attention," has not been addressed extensively in animal experiments. The present paper provides some data from an experiment on sustained attention with pigeons as subjects.

Sustained attention in humans has been studied in two ways. In the classic vigilance paradigm (Mackworth, 1970), observers monitor a perceptual display for long periods of time; the observers' objective is to detect sporadic changes in the display (signals). In other tasks, intersignal intervals are much shorter, and attention presumably varies with the proximity of a warning signal to the to-be-detected signal. Reports based on the latter

This research was supported by funds from NSF Institutional Grant for Science GU 3615 . Reprint requests should be addressed to William S. Maki Jr., Department of Psychology, North Dakota State University, Fargo, North Dakota 58102. class of tasks are emphasized here because they suggest what should be done to reveal fluctuations of sustained attention in animals.

In both choice reaction time and signal detection tasks, human performance is facilitated by the presence of a warning signal prior to the to-be-detected signal. Klein and Kerr (1974) found that detectability of a brief $(2 \mathrm{msec})$ signal was enhanced if it was preceded by an auditory warning signal. Posner, Klein, Summers, and Buggie (1973, Experiment II) used 40-msec or 400-msec stimulus times preceded by a warning signal. Warning signals decreased error rates, but only for stimuli presented for $40 \mathrm{msec}$. Posner et al. explained these results by assuming that warning signals shorten the time it takes the organism to begin processing the accumulated sensory information about the signal. For brief signals, the information decays rapidly, so speeded processing makes use of the information before it decays and therefore results in a more accurate response. The results of these experiments point to the importance of stimulus duration as a variable in studies of sustained attention; it appears that the effects of sustained attention will be most pronounced at shorter stimulus durations.

Many studies with animals also emphasize the importance of stimulus duration as a variable in the study of sustained attention. DeLorge, Hess, and Clark (1967) studied vigilance in monkeys. Detection latencies were used as measures of performance, but they were rather insensitive to manipulation of signal frequency. Since increases in the interval during which a signal may occur reduce signal detection by humans (Egan, Greenberg, \& Schulman, 1961), one might expect to see poorer performance with decreasing signal frequency. However, when signals in the DeLorge et al. experiment occurred, they remained on until terminated by a detection response, i.e., durations of the signals were effectively uncontrolled. 


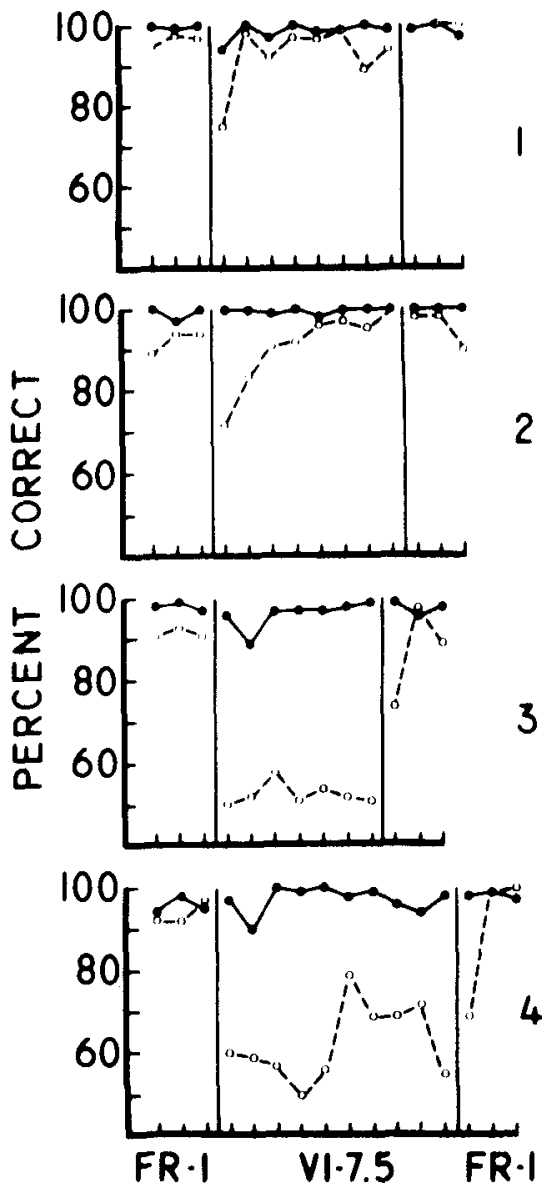

Figure 1. Percent correct (reinforced) choices as a function of schedule of cue production and cue duration. Open circles represent data from 0.2 -sec duration sessions, and filled ctrcles represent data from 2.0-sec cssiona. Data are presented separately for Birds 1-4.

Several other reports suggest wide variations in the degree to which brief stimuli support visual discrimination performances by monkeys. These variations can be accounted for by noting the transiency of the effects of warning signals. In the human performance studies cited above (Klein \& Kerr, 1974; Posner \& Boies, 1971; Posner et al., 1973), the effectiveness of warning signals depended on their proximity to the to-be-detected signal. Likewise, in those studies with monkeys, the proximity of some experimental event to the signal is correlated with performance. Both Chow and Orbach (1957) and Fuster (1958) report near chance performance at $10 \mathrm{msec}$, while Adkins, Fehmi, and Lindsley (1969) and Ettlinger, Ridley, and Hester (1973) report better than 90\% correct responding at exposure durations of $10 \mathrm{msec}$ or less. Fuster preceded exposure by $2 \mathrm{sec}$ with an "acoustic signal," and Chow and Orbach raised an opaque screen prior to a stimulus presentation. ${ }^{1}$ In the, other studies, monkeys made a cue-producing response
(CPR) which produced the stimuli immediately (Ettlinger et al.) or after $300 \mathrm{msec}$ (Adkins et al.).

The experiments cited above suggest the more prominent features of the present experiment. Pigeons' attention to a stimulus source was sustained by making discriminative stimuli $\left(S D_{S}\right)$ contingent on CPRs, i.e., the birds monitored a display. The degree to which attention was sustained was manipulated by changing the schedule of cue production; that is, the time interval during which a signal could occur was varied. Finally, the exposure duration of the $S_{D}$ s was also varied. The results of previous studies combined to predict the results of the present experiment: schedule of cue production and cue duration should interactively determine performance of a discrimination.

\section{Subjects}

\section{METHOD}

liour adult White Carneaux pigeons were maintained at $85 \%-100 \%$ of their free-feeding weights by food obtained during experimental sessions. Each bird had served in an immediately preceding discrimination learning experiment which was procedurally similar to that described below.

\section{Apparatus}

The experimental chamber was a Coulbourn Instruments (CI) modular environment housed in a $\mathrm{Cl}$ universal cubicle. An 82-dB masking noise was presented through a speaker mounted on the roof of the chamber. The front of the chamber held a grain hopper, house lights, and three pecking keys backed by inline projectors. The keys were arranged in a triangular display; the center key was located $20 \mathrm{~cm}$ above the grid floor of the chamber, and the side keys were located $19 \mathrm{~cm}$ above the floor and $16 \mathrm{~cm}$ apart. The grain hopper was located below the center key. The constant illumination of the house light, located above the center key, was directed toward the roof of the chamber.

Experimental events were controlled by a solid state logic system (BRS 200 series). Each peck on the center key presented a 50 -msec pulse to the logic system. Hence, responses following interresponse times of less than 50 msec were ignored. Various types of trials were programmed by a BRS punched paper tape reader. The schedules of cue production described below were accomplished with a BRS interval/ratio film programmer. Data were recorded on electro mechanical counters.

\section{Procedure}

liach session consisted of 100 trials. During the first part of the experiment, each trial commenced with the onset of a white disk on the center key. A single peck on the white disk, i.e., a $C P R$, resulted in the display of a red or green disk $\left(S^{D}\right)$ on the center key. During each pair of sessions, the SD remained on the center key $2.0 \mathrm{sec}$ during the first day and for $0.2 \mathrm{sec}$ the second day.

Pecks at the $S^{D}$, known as observing responses (ORs), were recorded but ineffective. Upon termination of the $S^{D}$, the side keys were illuminated by white disks. A peck at either side key darkened both side keys, and 5 sec later a new trial commenced. If the $S^{D}$ was a red disk, a peck on the right side key also resulted in reinforcement ( $2-\mathrm{sec}$ access to mixed grain); if the $S D$ was a green disk, a peck on the left key resulted in reinforcement. Red and green center keys were presented randomly from trial to trial, but with equal frequencies.

Each bird's discrimination performance stabilized above $90 \%$ correct (reinforced) responses for both cue durations over six to seven pairs of sessions. During the next part of the experiment, only one change in procedure occurred: the schedule of cue 
production was changed from fixed ratio (FR 1) to variable interval (VI $7.5 \mathrm{sec}$ ). That is, on the average, the first CPR after $7.5 \mathrm{sec}$ produced the $\mathrm{SD}$. A constant probability schedule was used (Catania \& Rejnolds, 1968, Pp. 380-381). The schedule was composed of 10 intervals, and the tape contained four randomized sequences of these 10 intervals. In all other respects, the procedures remained the same as those previously described. After seven to ten pairs of sessions, the birds were returned to three pairs of sessions of FR 1 cue production.

\section{RESULTS}

Figure 1 portrays the effects of changing schedules of cue production on control of side key choices as a function of $S^{D}$ duration. Data are presented from three pairs of sessions (FR 1) immediately prior and subsequent to the VI 7.5 sessions. Introduction of the VI 7.5 schedule reduced performance. The effect was most marked and persistent for Birds 3 and 4; Birds 1 and 2 also showed disruptions in performance, but to a lesser and transitory degree. When schedule of cue production reverted to FR 1, performance improved. Again, this effect was most noticeable in the data from Birds 3 and 4. It is most important to notice that both of these effects were confined to performances maintained by the shorter, $0.2-\sec S^{D_{s}}$.

Table 1 summarizes data on control of side key choices as a function of cue duration and schedule of cue production. Also presented are rates of responding during different stimulus events (white disk and $S^{D}$ ) on the center key. The data presented in this table are averages based on three pairs of sessions surrounding the transitions from FR 1 to VI 7.5, and from VI 7.5 to FR 1. Rates of ORs were derived by dividing total ORs in a given session by 100 (trials) times prevailing SD duration $(0.2$ or $2.0 \mathrm{sec} /$ trial). Despite idiosyncracies in the data, ${ }^{2}$ four effects seem to be present. First, $0.2 \mathrm{sec}$ $\mathrm{SD}_{\mathrm{S}}$ maintained a greater rate of CPRs during VI 7.5 cue production than did 2.0-sec $S^{D}$. Second, CPR rates increased with extended exposure to VI 7.5 cue production. Third, VI 7.5 cue production maintained a higher rate of ORs than did FR 1 cue production. Finally, in all but one instance (Bird 4, 0.2-sec SD), OR rates exceeded CPR rates during VI 7.5 sessions.

\section{DISCUSSION}

The major finding of the present experiment was that there is an interactive effect of schedule of cue production and cue duration on performance of a discrimination. These data point to the certainty with which an SD follows some other event (a CPR) as an important variable determining performance by brief cues. That is, reductions in the probability with which a given CPR initiates $S^{D}$ presentation (trials/CPR) result in reduced control by that $S D$.

The effects evident in Figure 1 might also have been due to confounded changes in two other quantifiable variables. First, rate of responding on the center key (resp/sec) was greater during VI 7.5 sessions. Second, the rate at which trials occurred (trials/min) was less during VI 7.5 sessions. Each of these possibilities will be dealt with in turn. It is very unlikely that $\mathrm{resp} / \mathrm{sec}$ is the variable responsible for changes in performance accompanying schedule shifts. Variations in both CPR and $O R$ rates across birds appear to be quite uncorrelated with concurrent variations in control by $0.2-\sec S^{D_{S}}$ (Table 1). Moreover, previous reports show

Table 1

Observing (OR), Cue-Producing (CPR) Response Rates, and Percentage Correct (\%C) Responses as a Function of Schedule of Cue Production and Cue Duration

\begin{tabular}{|c|c|c|c|c|c|c|c|c|c|}
\hline \multirow[b]{2}{*}{ Bird } & & \multicolumn{4}{|c|}{.2-Sec Duration } & \multicolumn{4}{|c|}{ 2-Sec Duration } \\
\hline & & FR & VI & VI & FR & FR & VI & VI & FR \\
\hline 1 & $\begin{array}{l}\text { OR } \\
\text { CPR } \\
\% \mathrm{C}\end{array}$ & 97 & $\begin{array}{r}1.25 \\
.81\end{array}$ & $\begin{array}{l}3.23 \\
1.12 \\
94\end{array}$ & $\begin{array}{r}.07 \\
100\end{array}$ & 100 & $\begin{array}{r}3.66 \\
.67 \\
97\end{array}$ & $\begin{array}{r}3.54 \\
.93 \\
99\end{array}$ & $\begin{array}{l}2.81 \\
99\end{array}$ \\
\hline 2 & $\begin{array}{l}\text { OR } \\
\text { CPR } \\
\% \mathrm{C}\end{array}$ & 92 & $82^{.93}$ & $\begin{array}{l}3.80 \\
1.08 \\
97\end{array}$ & $\begin{array}{l}2.40 \\
96\end{array}$ & 99 & $\begin{array}{r}3.05 \\
100^{.79}\end{array}$ & $\begin{array}{r}2.02 \\
1.03 \\
100\end{array}$ & 100 \\
\hline 3 & $\begin{array}{l}\text { OR } \\
\text { CPR } \\
\% \mathrm{C}\end{array}$ & $\begin{array}{r}.78 \\
92\end{array}$ & $\begin{array}{l}2.85 \\
1.66 \\
53\end{array}$ & $\begin{array}{l}6.25 \\
2.85 \\
52\end{array}$ & $\begin{array}{l}1.87 \\
87\end{array}$ & $\begin{array}{l}2.76 \\
98\end{array}$ & $\begin{array}{r}4.35 \\
1.43 \\
94\end{array}$ & $\begin{array}{l}5.27 \\
2.27 \\
98\end{array}$ & $\begin{array}{l}2.22 \\
98\end{array}$ \\
\hline 4 & $\begin{array}{l}\text { OR } \\
\text { CPR } \\
\% \mathrm{C}\end{array}$ & $\begin{array}{r}0 \\
94\end{array}$ & ${ }_{59}^{0} .85$ & $\begin{array}{l}.23 \\
65\end{array}$ & 89 & $\begin{array}{c}2.50 \\
96\end{array}$ & $\begin{array}{r}2.77 \\
.84 \\
96^{.84}\end{array}$ & $\begin{array}{l}2.02 \\
1.13 \\
96\end{array}$ & 1.89 \\
\hline Mean & $\begin{array}{l}\text { OR } \\
\text { CPR } \\
\% C\end{array}$ & $\begin{array}{r}.39 \\
94\end{array}$ & $\begin{array}{l}1.32 \\
1.06 \\
71\end{array}$ & $\begin{array}{r}3.38 \\
1.56 \\
77\end{array}$ & $\begin{array}{l}1.08 \\
93\end{array}$ & 2.63 & $\begin{array}{r}3.46 \\
.93 \\
97 \\
\end{array}$ & $\begin{array}{l}3.21 \\
1.34 \\
98 \\
\end{array}$ & 2.07 \\
\hline
\end{tabular}

Note-Data (in terms of responses per second and percentage correct discriminations) were averaged over three pairs of sessions surrounding schedule shifts between FR 1 and VI 7.5-sec cue production. ${ }^{2}$ 
increased stimulus control accompanying increased CPRs (D'Amato, Etkin, \& Fazzaro, 1968) and ORs (Eckerman, Lanson, \& Cumming, 1968; Farthing \& Opuda, 1974). In contrast, the present results show increased CPRs and ORs accompanied by decreased stimulus control.

Although of secondary concern, some of the schedule effects on response rates deserve special attention. Generally, frequencies of both ORs and CPRs were greater during VI 7.5 than during FR 1 sessions, but ORs cannot be dismissed as simple extensions of CPRs. It is widely known that VI schedules are characterized by "bursts" of responses with short interresponse time (IRTs), separated by much longer IRTs (Reynolds, $1968)^{3}$. Consequently, food reinforcement (or, in the present case, $S^{D}$ onset) is more likely to occur after a long IRT than after a short IRT. It might therefore be expected that the local response rate (a "burst") during the brief period after $S^{D}$ onset (or during a brief $S^{D}$ ) will be higher than the overall rate. This would account for the fact that $O R$ rates exceed CPR rates during $0.2-\sec S^{D}$ sessions, but it will not account for the fact that OR rates also exceed CPR rates during 2.0-sec sessions. If the increased $\mathrm{OR}$ rates during $0.2-\sec \mathrm{SD}_{\mathrm{S}}$ merely reflect selective measurement of high local rates of responding, then measurement of response rates over a longer period of time (a $2.0-\mathrm{sec} \mathrm{S}^{\mathrm{D}}$ ) should result in OR rates approaching CPR rates. Inspection of Table 1 indicates that this was clearly not the case. Therefore, it is conciuded that increased $O R$ rates relative to CPR rates do not represent a measurement artifact. Also, increased OR rates during VI 7.5 sessions relative to OR rates during FR 1 sessions are reminiscent of behavioral contrast observed under schedules of food reinforcement (e.g., multiple VI extinction). Note that the white key during VI 7.5 sessions signaled extended periods of time during which opportunity for food reinforcement was not available. None of this, however, implicates variations in either $\mathrm{OR}$ or CPR rates as causative factors in reduced control by short $S^{D_{S}}$ during VI 7.5-sec cue production.

The second variable confounded with trials/CPR is the rate at which trials occurred (trials/min); when trials/CPR declined from FR 1 to VI 7.5 sessions, trials/min also declined. Although no direct evidence exists, it does not seem likely that trials/min contributed to the effects of changing schedules of cue production in any simple way. In the present experiment, decreases in trials/min were accompanied by decreases in performance. In a related matching to sample task, increased intertrial intervals (decreased trials/min) improved performance (Holt \& Shafer, 1973).

By elimination, then, fluctuations in trials/CPR seem to account for major changes in discriminative performance maintained by brief $S^{D}$. However, in this experiment, the two schedules of cue production differed in two ways with respect to the relation between trials and CPRs. Either or both of the differences might be crucial in explaining the effect of schedule of cue production on performance. First, the average likelihood of a particular CPR producing an SD was less during the VI 7.5 than during the FR 1 schedule. Second, during FR 1, each CPR produced an $\mathrm{S}^{\mathrm{D}}$, while, during VI 7.5, the number of CPRs preceding each $S^{D}$ varied. That is, the two schedules differed with respect to both the mean and variance of trials/CPR, parameters which correspond to the average interval and the distribution of intervals in the VI $7.5 \mathrm{sec}$ schedule. The relative contributions of these two factors should be evaluated in future experiments. The effects of variations in trials/CPR can be assessed by comparing schedules of cue production with different mean intervals, e.g., VI 7.5 vs. VI 30 sec. The effect of changes in the variance of trials/CPR can be assessed by comparing fixed and variable interval schedules, e.g., FI 7.5 vs. VI $7.5 \mathrm{sec}$. (Of course, fixed and variable ratio schedules could also be used in such experiments.)

Even without results of such experiments, a tentative account of the present findings may be constructed. This view closely follows that of Posner and his associates (Klein \& Kerr, 1974; Posner \& Boies, 1971; Posner et al., 1973). Upon signal occurrence, information begins to be accumulated by the subject in a very short term store; if the signal is brief, the stored information decays rapidly. To the extent that processing of the information is delayed, less information is available to guide responding, so discrimination performance suffers. In studies of human performance, warning signals seem to improve performance by speeding the onset of processing. In studies of animal performance, CPRs may act as warning signals; brief stimuli preceded by CPRs produce more accurate discriminations (Adkins et al., 1969; Ettlinger et al., 1973) than do stimuli not preceded by CPRs (Chow \& Orbach, 1957; Fuster, 1958).

In the present experiment, prolonged observation of (sustained attention to) a stimulus source was required. This was accomplished by scheduling $\mathrm{SD}_{\mathbf{S}}$ contingent on the occurrence of CPRs and then manipulating the schedule of cue production. When the schedule shifted from FR 1 to VR $7.5 \mathrm{sec}$, the probability of any given CPR resulting in cue presentation decreased. Because this shift only affected control by brief stimuli, delayed processing of sensory information seems to be a plausible explanation of the effects of sustained attention. In other words, the reliability with which some event (e.g., a CPR) predicts a cue determines how effectively that event will prepare the organism to process information. How well this analysis survives the future experimentation suggested above remains to be seen. 


\section{REFERENCES}

Adkins, J. W., Fehmi. L. G., \& Lindsley, D. B. Perceptual discrimination in monkeys: Retroactive visual masking. Physiology and Behavior, 1969, 4, 255-259.

Catania, A. C., \& Reynolds, G. S. A quantitative analysis of the responding maintained by interval schedules of reinforcement. Journal of the Experimental Analysis of Behavior, 1968, 11, No. 3, Part 2.

Chow, K. L., \& Orbach, J. Performance of visual discriminations presented tachistoscopically in monkeys with temporal neocortical ablations. Joumal of Comparative and Physiological Psy chology, 1957, 50, 636-640.

D'Amato, M. R., Etkin, M., \& Fazzaro, J. Cue-producing behavior in the Capuchin monkey during reversal, extinction. acquisition, and overtraining. Journal of the Experimental Analysis of Behavior, 1968, 11, 425-433.

DeLorge, J. O., Hess, J., \& Clark, F. C. Observing behavior in the squirrel monkey in a situation analogous to human monitoring. Perceptual and Motor Skills, 1967, 25, 748-767.

Eckerman, D. A., Lanson, R. N., \& Cumming, W. W. Acquisition and maintenance of matching without a required observing response. Journal of the Experimental Analysis of Behavior, $1968,11,435-441$.

Egan, J. P., Greenberg, G. Z., \& Schulman, A. I. Interval of time uncertainty in auditory detection. Jourmal of the Acoustical Society of America, 1961, 33, 771-778.

Ettlinger, G., Ridley, R. M., \& Hester, N. S. Successive visual discrimination performance in the monkey with brief stimuli. Neuropsy chologia, 1973, 11, 477-480.

Farthing, G. W., \& Opuda, M. J. Transfer of matching-to-sample in pigeons. Journal of the Experimental Analysis of Behavior, $1974,21,199-213$.

Fuster, J. M. Effects of stimulation of brain stem on tachistoscopic perception. Science, 1958, 127, 150.

Holt, G. L., \& Shafer, J. N. Function of intertrial interval in matching-to-sample. Journal of the Experimental Analysis of Behavior, 1973, 19, 181-186.

Klein, R., \& Kerr, B. Visual signal detection and the locus of foreperiod effects. Memory \& Cognition, 1974, 2, 431-435.
Lindsay, P. H. Multichannel processing in perception. In D. I. Mostofsky (Ed.), Attention: Contemporary theory and analy sis. New York: Appleton-Century-Crofts, 1970.

Mackworth, J. F. Vigilance and attention. Baltimore: Penguin, 1970.

Maki, W, S. Jr. \& Leith, C. R. Shared attention in pigeons. Journal of the Experimental Analysis of Behavior, 1973, 19 , 345-349.

Maki, W. S., Jr., \& Leuin, T. C. Information processing in pigeons. Science, $1972,176,535-536$.

Posner, M. I., \& Boies, S. J. Components of attention. Psy chological Review, 1971, 78, 391-408.

Posner, M. I., Klein, R., Summers, J., \& Buggie, s. On the selection of signals. Memory \& Cognition, 1973, 1, 2-12.

Reynolds, G. S. A primer of operant conditioning. Glenview: Scott, Foresman, 1968

Sutherland, N. S., \& Mackintosh, N. J. Mechanisms of animal discrimination learning. New York: Academic Press, 1971.

Swets, J. A., Kristofferson, A. B. Attention. Annual Review of Psychology, 1970, 21, 339-366.

\section{NOTES}

1. Although not reported by Chow and Orbach (1957), it is here assumed that manually raising a screen takes at least 1-2 sec and certain auditory cues accompany the experimenter's actions.

2. Frequencies of ORs were not recorded initially. Therefore, these data do not exist for Birds 1 and 2 during their first exposure to FR 1 cue production.

3. While frequencies of different IRTs were not recorded, the birds were observed for lengthy periods of time during VI sessions. Each bird was often observed to respond in "bursts," and $\mathrm{SD}_{\mathbf{S}}$ appeared to occur most often after long IRTs.

(Received for publication September 16, 1974 . Revision accepted March 21, 1975.) 